\title{
Imigrante angolano e subjetividade em conflito: e(in)screver-se e resistir em blog $^{1}$ Angolan immigrant and subjectivity in conflict: writing and resisting in blog
}

\author{
Thiago André Rodrigues Leite*
}

RESUMO: Neste artigo, a questão da subjetividade do imigrante tem um lugar fundamental, em virtude de ela exercer e sofrer os efeitos de sua integração ao novo país ou ao lugar para onde se moveu e, por conseguinte, sua permanência nesse lugar ou sua volta ao lugar de origem. Interessa-nos a subjetividade do imigrante associada ao mundo virtual, visto que esse âmbito tem contribuído para a (re)configuração subjetiva. $\mathrm{Na}$ virtualidade, chamamos a atenção para os diários virtuais, $b \log s$, os quais se configuram como um lugar de se narrar, de se mostrar. Acreditamos que algumas narrativas em blog se relacionem a um exercício de escrita de si, a qual é uma via para a construção da subjetividade, visto que essa escrita acontece a partir de narrativas de si. Estas narrativas podem indiciar um movimento de resistência. Nesse sentido, objetivamos verificar, a partir da análise de narrativas de um blog, como um imigrante angolano faz esse possível movimento de resistência. No entanto, para este artigo, escolhemos uma narrativa para discutir os possíveis indícios de resistência, materializados em elementos discursivos, que apontariam para os conflitos na subjetividade desse imigrante angolano.

PALAVRAS-CHAVE: Imigração. Blog. Escrita de si. Resistência. Subjetividade.

\begin{abstract}
In this article, the matter of the immigrant subjectivity has a fundamental space, owing to it exerts and suffers the effects of his integration to the new country or to the new place to where moved and, therefore, his stay in this place or his return to the birthplace. We are interested in the immigrant subjectivity associated with the virtual world, since this scope has contributed to the subjective (re)configuration. In the virtual reality, we attract attention to the virtual diaries, blogs, which characterize as a space of self telling, of self showing. We believe that some narratives in blog are related to an exercise of self writing, which is a via to the construction of the subjectivity, because this writing happens from self narratives. These narratives can charge a movement of resistance. In this way, we aim at checking, from the analysis of narratives of a blog, how an Angolan immigrant makes that possible movement of resistance. However, to this article, we chose a narrative to discuss the possible charges of resistance, materialized in discursive elements, that would point to the conflicts in the subjectivity of this Angolan immigrant.
\end{abstract}

KEYWORDS: Immigration. Blog. Self writing. Resistance. Subjectivity.

\footnotetext{
${ }^{1}$ Este texto tem grande contribuição de orientação da Professora Dra. Carla Nunes Vieira Tavares, orientação essa de Área Complementar, pelo Programa de Pós-graduação em Estudos Linguísticos (PPGEL), da Universidade Federal de Uberlândia (UFU). Agradecemos a essa Professora a atenção, leitura e envolvimento empreendidos ao texto em questão. Além disso, gostaríamos de agradecer imensamente as contribuições dadas pela Professora Dra. Elzira Yoko Uyeno na qualificação de Área Complementar, as quais foram de suma importância para aprimorarmos nosso olhar em relação ao corpus analisado, bem como para reforçarmos nossas questões teóricas.

* Mestre em Estudos Linguísticos pelo Programa de Pós-gradução em Estudos Linguísticos (PPGEL), da Universidade Federal de Uberlândia (UFU). Doutorando pelo mesmo Programa. E-mail: thiago_leite81@yahoo.com.
} 


\section{Introdução}

Neste artigo, a questão da subjetividade do imigrante tem um lugar fundamental, em virtude de ela exercer e sofrer os efeitos de sua integração ao novo país ou ao lugar para onde se moveu e, por conseguinte, sua permanência nesse lugar ou sua volta ao lugar de origem. Cumpre dizer que tomamos partido pela noção foucaultiana de subjetividade, subjetividade essa referenciada no social e no discurso, mas engendrada pelo particular do sujeito.

Por se tratar de um assunto relacionado à imigração, vale lembrar que parece ser cada vez mais comum a saída do país de origem para outros países em busca de novas perspectivas para a própria vida. O programa Profissão Repórter (Rede Globo), de 31 de julho de 2012, conforme matéria intitulada Gringos no Brasil, mostra que "o bom momento da economia brasileira está trazendo muitos estrangeiros [imigrantes ${ }^{2}$ ] ao país", sobretudo os que são lusófonos. Ao se falar a mesma língua, há certa facilidade para o contexto de imigração. Entre os muitos imigrantes lusófonos, chamam-nos a atenção os imigrantes angolanos, posto que estes vêm para o Brasil comprar produtos, muitas vezes, básicos (roupas, calçados, etc.), a fim de revender tais produtos na Angola. Esse tipo de compra acontece, porque, segundo a matéria mencionada, "a Angola foi devastada por uma guerra civil que durou 27 anos. Por isso, quase tudo que se consome lá é importado". Em outras palavras, podemos dizer que a maior parte dos produtos consumidos nesse país é importada. Dada a devastação que a guerra civil provocou, muitos angolanos têm imigrado definitivamente para o Brasil.

A imigração é um processo que implica a (re)configuração subjetiva ${ }^{3}$. Esse processo é conflituoso para os imigrantes, visto que, ao mesmo tempo em que eles anseiam a imigração, podem a ela resistir. De toda forma, imigrar é sinônimo de passar por conflitos subjetivos, pois ter contato com uma cultura estrangeira e sua língua é ceder ou resistir, de certa maneira, a elas. Portanto, os imigrantes (ou não) estão sempre propensos a serem (re)formulados pelo Outro, que comparece, neste caso, como sendo a sociedade de acolhida e seus valores (sua cultura, sua língua, etc.).

\footnotetext{
${ }^{2}$ Estamos tomando o estrangeiro como o próprio imigrante, pois estar na terra do outro é, de alguma forma, ser estrangeiro e, portanto, imigrante. Minimamente, o fato de o imigrante ter contato com outra cultura e, também, com outra língua presentifica a alteridade na própria subjetividade.

3 A questão da "(re)configuração subjetiva" permite pensar que a constituição subjetiva é um processo, no sentido de estar em constante movimento, uma vez que ganha novos traços (elementos linguísticos, enunciativos e discursivos) a partir de processos de subjetivação. Em outras palavras, a constituição subjetiva está sujeita a ser rearranjada pelos processos de subjetivação. Isso indica que novos traços são sempre passíveis de virem a constituir a subjetividade do sujeito.
} 
Neste texto, interessa-nos a subjetividade do imigrante associada ao mundo virtual, visto que esse âmbito tem contribuído para a (re)configuração subjetiva. $\mathrm{Na}$ virtualidade, chamamos a atenção para os diários virtuais, blogs, os quais se configuram como um lugar de se narrar, de se mostrar. Os blogs constituem um gênero em que os bloguistas dizem de si, de maneira a serem ouvidos e, muitas vezes, aconselhados pelos internautas. Essa espécie de abertura promovida pela virtualidade indicia que a intimidade não é mais tão íntima, ou melhor, muito da esfera privada torna-se público. Por isso, “(...) a virtualização, ao contrário de decretar a morte do homem como se teme, inaugura uma nova forma de subjetivação e, portanto, uma nova ontologia" (UYENO, 2004, p. 12). Os blogs são uma prova cabal de que a virtualidade permite a emergência de novos modos de subjetivação ${ }^{4}$, haja vista que levam os bloguistas, por vezes, a desabafarem, havendo uma emergência significativa de narrativas. Essa emergência fundamenta nossa opção por esse gênero textual em detrimento de tantos outros gêneros textuais.

De acordo com Uyeno (2005), diferente dos diários tradicionais (não virtuais), os quais permitem o desabafo em silêncio, os diários virtuais permitem a ocorrência de diagnósticos, atestando seu efeito terapêutico. Conforme Uyeno (2005, p. 39), "por um efeito terapêutico, ao enunciar a experiência das faltas que cometeu e receber de seu leitor uma crítica, compreensão ou quaisquer comentários, o blogueiro [bloguista] se sente penitenciado, o que lhe permite vislumbrar a cura da angústia". Os blogs parecem servir, então, como um gênero de exposição de si para que os outros (des)aprovem aquilo que vai sendo escrito sobre si. Aquele que confessa em blog aguarda, de certa forma, ser avaliado para tirar suas próprias conclusões acerca de si. Essa questão da avaliação pelo outro marca o caráter de relevância desse gênero textual relacionado à virtualidade. Os bloguistas, ao desabafarem em blog, podem encontrar eco em comentários, sendo, talvez, por isso, que os blogs têm a sua popularidade.

As narrativas em blog podem estar relacionadas a um exercício de escrita de $\mathrm{si}^{5}$, a qual é uma via para a construção da subjetividade, uma vez que essa escrita acontece a partir de

\footnotetext{
${ }^{4}$ A partir da perspectiva foucaultiana, entendemos que os "modos de subjetivação" dizem respeito às práticas de relação de si que permitem a alguém se constituir sujeito de sua própria existência. No tópico 3. Sujeito (posição discursiva) e subjetividade: modos de objetivação e subjetivação, aprofundamos um pouco esse conceito.

5 "Escrita de si" é um termo foucaultiano que aponta para uma prática de linguagem específica em que há um dizer de si. Vale lembrar que essa prática antecede Foucault, não sendo, pois, uma invenção foucaultiana.
} 
narrativas de si. Estas narrativas podem indiciar um movimento de resistência ${ }^{6}$ a se identificar e a se deixar afetar pela cultura do outro, resistindo, assim, a ser subjetivado pelo e a subjetivar o outro. Assim, a partir das narrativas do blog "angolacontecomigo.blogspot.com.br", de Santareno (imigrante angolano), construímos nosso material de pesquisa. Nesse sentido, objetivamos verificar, a partir da análise dessas narrativas, como esse imigrante angolano faz esse possível movimento de resistência.

No entanto, para este artigo, escolhemos uma narrativa, intitulada "Que confusão...", para discutir os possíveis indícios de resistência, materializados em elementos discursivos, que apontariam para os conflitos na subjetividade desse imigrante angolano. 0 exercício de análise foi norteado pelas seguintes perguntas: pautando-nos na narrativa “Que confusão...”, há indícios de resistência, no exercício da escrita de si, aos efeitos que a imigração possa ter sobre a (re)configuração subjetiva do imigrante angolano? Que possível funcionamento discursivo permite perceber tais indícios?

Entendemos que esses indícios, elementos discursivos, remeteriam a traços de subjetividade. Afirmamos haver "traços de" e não "a" subjetividade, porque, de acordo com Coracini (2007, p. 24), “é no exato momento em que [o sujeito] se submete às expectativas do outro - ou talvez por isso mesmo -, que resyalam, cá e lá, fragmentos, fagulhas candentes da subjetividade que (se) diz". Estamos tomando esses fragmentos (fagulhas) como traços de subjetividade e não como a subjetividade, visto que esta, por ser construída ao longo da vida, não é passível de ser "agarrada" completamente.

Sobre a estrutura deste texto, em um primeiro momento, discorremos sobre a constituição do gênero blog. Depois, sobre uma possível relação entre as noções de sujeito, subjetividade e modos de subjetivação. Em seguida, falamos acerca das noções de escrita de si e de resistência. Por fim, discutimos a narrativa em questão e tecemos nossas considerações finais

\footnotetext{
6 Minimamente, a resistência, segundo Foucault (1995), constitui o poder. Este, por sua vez, leva a manifestações de resistência, conforme procuramos discorrer mais adiante.

${ }^{7}$ Consideramos oportuno salientar que há uma pequena quantidade de blogs de imigrantes lusófonos no Brasil.
} 


\section{Blog e sua constituição: exposição de si}

O blog, como parte integrante do mundo da virtualidade, permite aos bloguistas que escrevam de uma maneira informal, no sentido de uma escrita "livre"8 de certas normas padrões, aproximando-se do modo cotidiano, coloquial, de (se) dizer. Dessa maneira, uma das características do blog dá-se pela incidência da oralidade na escrita. Referindo-se a essa característica, mas pontuando outras também, Coracini (2011, p. 27) afirma que

os blogs ou diários virtuais, também denominados ciberdiários, consistem numa escrita anônima, em que é possível falar de si a um outro totalmente desconhecido, numa linguagem não convencional, ou melhor, numa linguagem que, embora ancorada nas normas convencionais da escrita, apresenta outras características, dentre as quais se destacam as abreviações, as frases curtas e diretas, a escrita oralizada, a criação de neologismos.

Interessante observarmos que os bloguistas escrevem a (des)conhecidos. Tendo em vista que há certa projeção quando se está escrevendo, então há um leitor conhecido para quem a escrita de um determinado blog se endereça. Entretanto, não há garantia de que esse leitor em específico vá ler tal escrita. Por outro lado, pelo próprio fato da virtualidade, há um leitor desconhecido, leitor esse que se configura como anônimo. Como o gênero textual blog está disponível on-line, é impossível conhecer todos os seus leitores (os que já leram e os que lerão, por exemplo, um determinado blog), o que aponta para a característica indeterminada do blog, característica essa do próprio mundo virtual. Há casos em que um dado vídeo é postado na internet e, quando menos se espera, esse vídeo pode vir a se tornar um sucesso em âmbito nacional e, até mesmo, internacional, o que mostra a impossibilidade de determinação de seus leitores.

Por ser $\mathrm{o}$ anonimato uma das características essenciais da internet, muitos internautas se expõem. É por isso que, quanto mais houver a exposição de si nesse espaço, pensando especificamente em $b \log _{S}$, mais estes poderão ter a chance de serem acessados, comentados e recomendados. Essa exposição tem relação com a noção de sujeito do espetáculo, sujeito esse que vem como decorrência da sociedade definida por Debord (1997) como a sociedade do espetáculo. Para Debord (1997, p. 17),

\footnotetext{
${ }^{8}$ A palavra "livre" está entre aspas, porque, apesar de o gênero blog não exigir a conformação às exigências da gramática normativa, há regras intrínsecas ao próprio gênero que fazem com que qualquer escrita esteja subordinada a certa norma. Isso significa que a língua permite diferentes possibilidades de emprego.
} 
a sociedade que se baseia na indústria moderna não é fortuita ou superficialmente espetacular, ela é fundamentalmente espetaculoísta. No espetáculo, imagem da economia reinante, o fim não é nada, o desenrolar é tudo. O espetáculo não deseja chegar a nada que não seja ele mesmo.

A exposição de si é resultado do fato de que se vive na sociedade do espetáculo. De certa forma, estar nas redes sociais é fazer parte dessa exposição, visto que, geralmente, os internautas postam fotos pessoais, escrevem pensamentos próprios, colam links de vídeos que os chamam a atenção, etc. Coracini (2011, p. 39) acrescenta que, na sociedade do espetáculo, reality shows, "cada um exibe a sua intimidade, os seus segredos, para gozar e provocar o gozo no outro". A exibição da própria intimidade revela um modo específico de subjetivação que conforma o indivíduo em sujeito.

Há semelhança entre os diários não virtuais e os diários virtuais, pensando especificamente no caráter não estático de ambos. Conforme Coracini (2011, p. 29), “embora constitua um gênero distinto dos diários-papel, o blog é atravessado por eles, ou melhor, é por eles constituído", de tal forma que há uma estrutura discursiva de funcionamento parecida entre eles. Assim como nos diários não virtuais, há, nos blogs, um contar o cotidiano, característica essa que aponta para um dos aspectos de constituição dos blogs enquanto gênero de e para a escrita de si. No entanto, parece que traços de subjetividade aparecem mais nos $b \log s$, pois eles tendem, ao contrário dos diários não virtuais, a não serem feitos diariamente, mostrando que não há a "obrigação" de ali se escrever todo dia. Isso aponta para uma possível diferença entre os blogs e os diários não virtuais. Dessa maneira, os blogs não são exatamente diários tradicionais.

Outra semelhança entre esses gêneros textuais incide na presença do não verbal: fotos, desenhos, imagens em geral, etc. Essa presença, assim como a própria questão da caligrafia (em diários não virtuais) e da fonte da letra (em diários virtuais), pode indiciar certos sentidos em detrimento de outros e a possibilidade de certas posições discursivas e não outras. A realização de leituras e reflexões posteriores por parte de quem escreve os diários virtuais e não virtuais fundamenta mais uma semelhança entre tais gêneros. Como os blogs levam a uma exposição de si por meio da escrita, diríamos que esse gênero evoca uma escrita de si, abrindo para a configuração de uma posição discursiva específica e para possíveis traços de subjetividade daquele que ali se e(in)screve. 


\section{Sujeito (posição discursiva) e subjetividade: modos de objetivação e subjetivação}

Na perspectiva foucaultiana, pensar o sujeito como posição discursiva pressupõe um determinado funcionamento em um dado discurso. Este permite que alguém enuncie daquela posição e tenha, assim, seu dizer validado. Desse modo, o sujeito é resultado de relações discursivas, o que implica considerar o histórico e o social na sua constituição.

O sujeito imigrante é exemplo de posição discursiva, uma vez que essa forma de se posicionar enquanto sujeito é produto das práticas discursivas daqueles que partem do país de origem para outros países e daqueles que os recebem. Essas práticas, que são resultados das relações humanas constituídas no discurso, mostram que o sujeito tem sua gênese como objeto sócio-historicamente constituído, assim como a subjetividade. No entanto, apesar de objetivados socialmente para advirem como sujeitos, os indivíduos "trabalham a relação que os liga a si mesmos, se produzem e transformam" (REVEL, 2006, p. 85). Consequentemente, a subjetividade é constituída e se constitui na articulação entre os modos de objetivação, de subjetivação e do trabalho sobre si. Subjetividade, portanto, não pode ser confundida com posição discursiva. Por exemplo: a posição discursiva do sujeito imigrante pode ser ocupada por qualquer imigrante, entretanto pode ser ocupada subjetivamente, de sorte que seja possível perceber traços de subjetividade daquele que a ocupa.

Nesse sentido, consideramos imprescindível pensar no que diz Foucault (1995) sobre fazer da vida uma obra de arte, pois remete ao trabalho da subjetividade sobre si, (des)acomodando e subjetivando as subjetivações . De acordo com Foucault (1995, p. 270), os antigos

agiam, antes, de modo a conferir a suas vidas certos valores (reproduzir certos exemplos, deixar uma alta reputação para a posteridade, dar o máximo possível de brilhantismo às suas vidas). Era uma questão de fazer da vida um objeto para uma espécie de saber, de uma técnica, de uma arte.

Fazer da vida, da subjetividade, uma espécie de obra de arte, é uma obra que é sempre da ordem do singular, vivenciada singularmente, embora construída socialmente. Assim, subjetivação não pode ser compreendida como submissão, como assinala Sales (2008, p. 03):

a subjetivação se opõe à sujeição. Ela consiste em um processo de construção de si mesmo, no sentido de fazer da vida uma obra de arte. Há, pois, um cuidado de si, uma prática de si, uma política de si, um exercício de si sobre si que visam, acima de tudo, uma soberania sobre si mesmo. O que 
está em jogo é a técnica que deve ser utilizada para se viver da melhor maneira possível.

Os modos de subjetivação têm a ver com uma construção de si, a qual pode advir, por exemplo, das mudanças que a outra cultura (e a língua está aí inclusa) provoca no imigrante. Os modos de subjetivação constituem os processos de subjetivação. De acordo com Uyeno (2011, p. 205),

os processos de subjetivação se constituem de duas formas: pelos modos de objetivação que engendram os sujeitos, por um lado, e pelas maneiras por meio das quais o indivíduo se constitui como sujeito de sua própria existência, por outro [modos de subjetivação].

Em outras palavras, falar em subjetividade a partir dos modos de objetivação e subjetivação é falar da inseparabilidade entre aquilo que é da ordem do social e aquilo que vai sendo construído pelo sujeito ao longo da vida. Assim, a subjetividade é moldada sóciohistoricamente, mas também tem algo do particular do sujeito, podendo se manifestar via alguns traços na escrita de si.

\section{Escrita de si: (re)significando-se}

Tendo em vista que nosso foco de análise recai na escrita de si que se dá via blog, julgamos fundamental esclarecer que, de acordo com Foucault (1992, p. 150), “escrever é (...) 'mostrar-se', dar-se a ver, fazer aparecer o rosto próprio junto ao outro". Escrever é contar de si, dada a possibilidade de serem entrevistos, nas relações entre as palavras, traços de subjetividade daquele que escreve. Segundo Uyeno (2006, p. 03), “em quaisquer que sejam os ciclos de exercício, a escrita constitui uma etapa essencial no processo de constituição do sujeito". Em qualquer que seja o suporte para a escrita, o sujeito tem de assumir certas condições para marcar uma diferença a partir do modo como executa narrativas de si. Essas narrativas dizem respeito à escrita de si, que visa à subjetivação.

Vale lembrar que a escrita de si nasce com os gregos ao escreverem e realizarem um exame pessoal para não executarem determinada ação, já que, nessa perspectiva, era preciso purificar-se e, desse modo, tornar-se melhor, promovendo uma espécie de aperfeiçoamento moral. Isso permite afirmar que, conforme Foucault (1992, p. 141), 
a escrita como exercício pessoal praticado por si e para si é uma arte da verdade contrastiva; ou, mais precisamente, uma maneira reflectida de combinar a autoridade tradicional da coisa já dita com a singularidade da verdade que nela se afirma e a particularidade das circunstâncias que determinam o seu uso.

Relacionar a escrita de si a "uma arte da verdade contrastiva" leva-nos a compreender que essa escrita, ao articular passado e presente em diferentes circunstâncias, é uma via que diz respeito à constituição de si, da subjetividade. A escrita de si aponta para a demanda de (re)significação, instaurada não só a partir do sujeito que e(in)screve-se, mas também do histórico-social, que interpela o sujeito, de modo a objetivá-lo e determinar-lhe uma posição a ser assumida no discurso.

Concordamos com Uyeno (2004, p. 11) quando postula que "não há como negar que o ato de falar da experiência de si para outrem seja motivado pela necessidade de revelar que se é constituído de uma singularidade". Alguém pode ou não criar um blog, porém, se há a criação de um, ali pode se materializar uma demanda de narrar de si. Esse tipo de narrar indica que toda vez que se diz de si é sempre um não dizer a mesma coisa, ou seja, é um movimento de narrativização. A escrita de si, que é um exemplo de movimento de narrativização, pode ocorrer de diferentes modos e, por conseguinte, pode marcar diferentes formas de manifestações de resistência.

\section{Resistência: poder, opacidade e oposição}

Para tratar da questão da resistência, partimos da perspectiva foucaultiana, a qual diz que a resistência se manifesta nas mais diferentes relações humanas. Essa perspectiva permite pensar que não há uma única forma de resistência, sendo esta vinculada ao exercício do poder. Segundo Foucault (1995, p. 13), “só há poder exercido por 'uns' sobre os 'outros'; o poder só existe em ato, mesmo que, é claro, se inscreva num campo de possibilidade esparso que se apóia sobre estruturas permanentes". Essa existência "em ato" do poder aponta para o seu caráter relacional, haja vista que aquele que está exercendo poder, em um dado momento, pode não mais está-lo em outro momento. Para Foucault (2006, p. 277),

(...) nas relações de poder, há necessariamente possibilidade de resistência, pois se não houvesse possibilidade de resistência - de resistência violenta, de 
fuga, de subterfúgios, de estratégias que invertam a situação -, não haveria de forma alguma relações de poder?.

Só há poder, porque pode ocorrer resistência, a qual pode se manifestar discursivamente por meio de certas marcas linguísticas, como, por exemplo, um advérbio de intensidade (mais), uma conjunção adversativa (mas), entre outras. Isso não quer dizer que toda vez que um "mais" ou "mas" emirja vai haver resistência, já que não estamos defendendo que os sentidos de resistência são inerentes às palavras. Pelo contrário, eles são construídos na relação que estabelecem entre si na cadeia discursiva, na dependência das condições de produção dos enunciados ${ }^{10}$, sendo a posição sujeito integrante decorrente dessas condições.

A resistência que estamos focando não se apresenta de forma transparente, mas, sim, de maneira sutil. Tendo em vista que consideramos a resistência via linguagem, a qual é, de nossa perspectiva, opaca, logo a resistência via linguagem também o é. Além dessa característica de opacidade para a resistência, destacamos que, por sempre se manifestar mediante algum tipo de oposição, esta configura-se, também, como outra característica para a resistência. Por isso, cabe dizer, juntamente com Guattari (2000, p. 45), que

a tentativa de controle social, através da produção da subjetividade em escala planetária, se choca com fatores de resistência consideráveis, processos de diferenciação permanente que eu chamaria de 'revolução molecular'. Mas o nome pouco importa.

Essa revolução é uma espécie de oposição ao que está socialmente posto. E tal revolução, resistência, pode acontecer de modo inconsciente, uma vez que, muitas vezes, o sujeito resiste sem saber ou perceber que está resistindo, levando-se em conta certos funcionamentos discursivos que indiciam conflito na subjetividade.

\section{Subjetividade em conflito: ser e/ou estar angolano e/ou brasileiro?}

O imigrante, ao se instalar, temporariamente ou não, na terra do outro, não é mais o mesmo de quando partiu de sua terra de origem. Contudo, não é também como aquele da

\footnotetext{
${ }^{9}$ A inexistência do exercício do poder por conta da impossibilidade de resistência é associável a um exemplo dado por Foucault (1995, p. 15) ao dizer que “(...) a escravidão não é uma relação de poder, pois o homem está acorrentado (trata-se então de relação física de coação) (...)”.

10 "Enunciado", nos estudos foucaultianos, se refere ao modo de existência de um conjunto de objetos e sujeitos, permitindo que, por sua propriedade de repetibilidade, seja relacionado com outras formulações.
} 
pátria de acolhida. Assim, o imigrante parece não ter um ponto fixo, estando sempre em trânsito. Isso é corroborado por Kristeva (1994, p. 15) ao dizer que

não pertencer a nenhum lugar, nenhum tempo, nenhum amor. A origem perdida, o enraizamento impossível, a memória imergente, o presente em suspenso. $O$ espaço do estrangeiro [imigrante] é um trem em marcha, um avião em pleno ar, a própria transição que exclui a parada. Pontos de referência, nada mais. $\mathrm{O}$ seu tempo? $\mathrm{O}$ de uma ressurreição que se lembra da morte e do antes, mas perde a glória do estar além: somente a impressão de um sursis, de ter escapado (grifos nossos).

Apesar de a subjetividade do imigrante estar em constante suspensão, há pontos de apoio, ou melhor, "pontos de referência", para a própria existência de si. Tais pontos, que dizem respeito à subjetivação que se faz do mundo, apontam para a ilusão de centralidade. Esse exemplo de mudança subjetiva permite afirmar que o imigrante é uma espécie de "trem em marcha" ou “avião em pleno ar". Entretanto, pensando nessas metáforas, é possível dizer que tanto o trem como o avião hão de parar em algum lugar. Assim, as metáforas em questão levam a refletir sobre a escrita de si como indiciadora de um lugar no qual o imigrante pode vir a se agarrar para a existência de si, lugar esse de possível resistência.

Articulamos tal lugar de possível(r)existência ao blog de Santareno intitulado "angolacontecomigo.blogspot.com.br", pensando especificamente em uma dada narrativa. Esse blog não é convencional, já que não há um copiar e colar pensamentos, fotos, etc. Nem mesmo há informação sobre a idade de Santareno. Há apenas a menção de que ele é do sexo masculino e de que seu segundo nome é Augusto. Além disso, há a menção de que segue um blog intitulado "psi-comunitaria.blogspot.com.br".

Santareno criou seu blog em dezembro de 2010. Nesse mesmo ano, postou quatro narrativas, quais sejam, "Coisas de viagem", "Como a internet faz falta...", "Bom dia! Você tem o pão do dia?" e "Surpresas e trocas de presentes". No ano de 2011, postou três narrativas. "Mais um dia...", "Que confusão..." e "Luanda no final de semana". Em 2012, não postou nenhuma narrativa. E, até abril de 2013, não postou nenhuma narrativa também. Portanto, de 2010 até esta data, há sete narrativas. Essas escritas esparsas levam-nos a refletir sobre a ideia de que Santareno não tinha interesse em ser ouvido, mas, sim, em ter escrito, o que parece configurar o efeito terapêutico da escrita. Esse efeito, no caso da narrativa a ser discutida, pode ser associado à exposição da angústia de querer ser aceito pelos angolanos e/ou pelos brasileiros. 
Analisamos as narrativas acima mencionadas, mas este artigo recorta uma delas, "Que confusão...”, e mostra o resultado de análise. Nesta narrativa, mesmo em uma primeira leitura, foi possível perceber, de certa forma, uma escrita de si produzindo manifestações de resistência, aqui analisada especificamente mediante certos elementos linguísticos, no caso, dêiticos ${ }^{11}$, definidos mais adiante. Cumpre dizer que elegemos como categoria linguística de análise alguns dêiticos, uma vez que parecem mostrar indícios de conflitos na subjetividade, devido à desestabilização de sentidos dos dizeres em que estão inseridos. Realizamos, em tal narrativa, um recorte para empreendermos nossa análise. Esse recorte segue abaixo.

Estou fora de Angola há muito tempo (16 anos), faz tempo. Para alguns eu já sou brasileiro, para outros ainda sou angolano, mas com muitas mudanças. Para Rafael e Samuel nossos filhos, Angola é sua segunda pátria, pois eles nasceram no Brasil. O Rafael já cá esteve, essa é a terceira vez que vem. A princípio estranhou as pessoas e o ambiente, mas agora já está enturmado, mas já perguntou quando é que vamos embora. Para a Beth aqui é terra dela, ainda conserva o sotaque do português angolano. Algumas pessoas a elogiam por não perder o sotaque do português angolano, já no meu caso é diferente. Sofro criticas, e são muitas, dizem que eu sou brasileiro.

Quando estamos com os familiares, quase dizem sempre: Oh, a Beth mudou pouco, já o Santareno está brasileiro. Isso pode parecer um elogio, mas é uma critica. As criticas se referem apenas ao meu sotaque ${ }^{12}$.

De início, chamamos a atenção para o nome do blog: “angolacontecomigo.blogspot.com.br". Esse nome permite inferir o sentido de que Santareno mostra seu amor à pátria, posto que o termo "angola", em tal nome, funciona como um vocativo, isto é, um chamamento para, possivelmente, dizer que os angolanos podem contar com todo o seu apoio, dado o possível fato de se considerar como um autêntico angolano. $\mathrm{O}$ nome "angolacontecomigo.blogspot.com.br" rememora a expressão "pode contar comigo", a qual é comum ouvirmos entre familiares e/ou amigos em situações de problemas, como, por exemplo, situações de enfermidade. Essa expressão produz sentidos associáveis a expressões como: "sou parte de vocês", "considero-me um de vocês", etc.

A própria invocação pressuposta na frase: “Angola, conte comigo” já enseja um indício de resistência. A frase soa como um clamor, uma resposta a um recrutamento indizível, mas

\footnotetext{
${ }^{11}$ Provavelmente, deve haver outras manifestações de resistência via outros elementos linguísticos no fragmento da narrativa "Que confusão...", mas, a título de recorte e de intensa manifestação de resistência, optamos somente por alguns dêiticos e por uma conjunção.

${ }^{12}$ Esse recorte foi copiado tal qual se encontra no blog de Santareno, por isso qualquer desvio da norma padrão do português brasileiro não foi corrigido.
} 
que conclama o sujeito a se posicionar. Parece também soar como um lembrete aos seus de que, embora longe de seu país de origem e, portanto, imerso no país de acolhida, algo de si ainda resiste e se reconhece como parte integrante de um povo.

Também, chamamos a atenção para o próprio título da narrativa: "Que confusão...". Esse título já sugere certo conflito na subjetividade do imigrante angolano. Vale dizer que o caráter confusão constitui o gênero blog, visto que é muito comum se dizer, nesse gênero, sobre aquilo que não deu ou não dá certo na vida, o que pode indiciar conflito na subjetividade.

Na narrativa "Que confusão...", a questão da ambiguidade, do conflito,é possível ser percebida no tom de lamentação mediante o emprego de dêiticos. Segundo Ilari (2006, p. 55), “a palavra 'dêitico' contém a idéia de apontar, e as expressões dêiticas mais típicas apontam para elementos fisicamente presentes na situação de fala". Optamos pelos dêiticos por apresentarem (maior?) possibilidade de falarmos sobre manifestações de resistência via uma escrita de si. Isso parece corroborar a ideia de que, para Guimarães (1999, p. 11), "os dêiticos se identificam como os elementos lingüísticos que mais claramente mostram a presença do emissor no enunciado". No caso do imigrante angolano Santareno, os dêiticos concretizam, a nosso ver, o processo de deriva de sua subjetividade.

No início de sua narrativa, o imigrante angolano em questão afirma estar fora de Angola há 16 anos. Em seguida, afirma: "para alguns eu já sou brasileiro, para outros ainda sou angolano, mas com muitas mudanças" (grifos nossos). Inicialmente, chamamos a atenção para as expressões "para alguns" e "para outros", as quais parecem mostrar que o outro tem a chave sobre Santareno, podendo liber(t)á-lo pela penitência que aplica. É como se Santareno se sentisse culpado por não ser brasileiro (porque deseja ser aceito pelos brasileiros) e por não mais ser angolano (porque deseja continuar considerado angolano pelos angolanos).

Em uma incidência de enunciado de Santareno, destacamos a presença de dois dêiticos: "já" e "ainda". Esses dêiticos apontam para referentes diferentes advindos de uma prática de linguagem concretizada na escrita de si, embora ambos os dêiticos se configurem como temporais e espaciais. "Já" ser brasileiro e "ainda" ser angolano marcam tempo e território: "já" (tempo presente que marca Santareno como sendo, em certo sentido, brasileiro) e "ainda" (tempo presente que marca Santareno como sendo, em certo sentido, quase brasileiro). Em todo caso, os dêiticos em questão parecem indiciar um movimento específico 
de resistência: deixar de ser angolano, posto que, em termos familiares, isso seria uma traição à tradição. O título do blog parece se remeter a uma resposta do sujeito a essa suposta traição.

O dêitico "já" deixa entrever que Santareno é, de certo modo, um brasileiro, pensando na relação que ele trava com a língua falada no país de acolhida, indiciada no seu possível sutil sotaque. Por outro lado, o dêitico "ainda" indicia o traço que liga Santareno ao seu país de origem, o mesmo sotaque angolano, que o denuncia como estrangeiro. Esse jogo de dêiticos permite refletir acerca da ambiguidade experimentada na posição discursiva de imigrante: ser um pouco o outro, mas sem se exilar totalmente. Escancara-se, assím, a subjetividade conflitante e resistente do imigrante, que busca atender à demanda do outro, mas resiste a ser (re)moldado por completo.

A subjetividade vivenciada na singularidade de uma existêncía só pode ser vivida ou experimentada e construída, como uma obra de arte, pela resistência. Esta impele-nos a perguntar: resistência a quê? Diríamos que é a resistência ao modo pré-fabricado de existir que a sociedade impõe sobre o indivíduo. Uma das vias para este alçar-se a sujeito é pela resistência, a qual diz respeito ao modo singular com que alguém advém como sujeito, daí obra de arte. Em suma, exercer a subjetividade, como uma obra de arte, só é possível se houver resistência por parte do sujeito.

A resistência de que tratamos se manifesta mediante indícios presentes numa escrita de si, o que nos leva a destacar a incidência do enunciado a seguir. "Para a Beth aqui é terra dela, ainda conserva o sotaque do português angolano. Algumas pessoas a elogiam por não perder o sotaque do português angolano, já no meu caso é diferente. Sofro criticas, e são muitas, dizem que eu sou brasileiro" (grifos nossos). Interessante observar que o dêitico "aqui", no início do enunciado, é equívoco. Isso porque permite perguntar: tal dêitico refere-se a Angola por Beth conservar, em certo sentido, o sotaque angolano, ou ao Brasil, embora Beth tenha aspectos desse sotaque? De todo modo, esse "aqui" pode ser entendido não como o lugar geográfico, mas como a própria língua, ou seja, a terra de Beth seria o sotaque angolano não perdido. Entretanto, ressaltamos que o dêitico "ainda" apresenta um tom de que Beth, possivelmente esposa de Santareno, possa perder o sotaque angolano com o passar do tempo, indicando que ela, de toda forma, tem (conserva) esse sotaque.

Santareno parece ressentir-se com o fato de ser identificado pelo outro de seu país como brasileiro, devido ao seu modo de falar, o que pode ser entrevisto no termo "já", o qual não funciona como um dêitico, mas, sim, como uma conjunção adversativa. Essa conjunção 
marca um sentido diferente daquele que estava operando anteriormente no próprio enunciado, porque, à medida que Beth conserva o sotaque angolano, Santareno, ao olhar do outro, perdeu esse sotaque, de sorte que afirma: "sofro criticas, e são muitas, dizem que eu sou brasileiro".

Santareno, ao tomar para si o dizer do outro sobre ele mesmo ("algumas pessoas", “dizem”), deixa entrever um modo de objetivação, mas também um modo de subjetivação. A palavra do outro tem esse duplo efeito: tanto objetivar o sujeito como subjetivá-lo. São os modos de objetivação que submetem o imigrante angolano a um processo que vai se transformando em subjetivação, de maneira que afirma "sofro criticas". Ao dizer que sofre críticas por ser visto como brasileiro, Santareno indicia uma resistência ao fato de não querer se deixar afetar pelo modo de falar brasileiro, associando a ideia de ser brasileiro a uma crítica e não, por exemplo, a um elogio. No entanto, essa resistência não sugere que Santareno deixe de ser afetado pelos vários modos de falar o português brasileiro.

A afetação em questão permite reforçar os processos de subjetivação foucaultianos. Isso porque tais processos estão ligados aos modos de objetivação (como o momento sóciohistórico submete o sujeito ao poder e o constrói) que, no caso de Santareno, parecem submetê-lo aos vários modos de falar o português brasileiro para se ver aceito. Também, estão ligados aos modos de subjetivação (aqui, especificamente, resistência ao poder, mostrando que, conforme dizeres foucaultianos, o poder, na maior parte das vezes, é produtivo) que, no caso do imigrante angolano, parecem vir nas possíveis manifestações de resistência via escrita de si, mas também no consentimento ao português brasileiro e a como esse português o faz parecer brasileiro aos olhos do outro.

Na percepção de Santareno, Beth guarda uma subjetividade "incontaminada", o que a colocaria como um sujeito sem conflito no que diz respeito a sua posição de imigrante. Santareno, ao contrário, parece sentir que sua subjetividade está sendo o tempo todo colocada à prova, de sorte que escreveu uma narrativa (acerca) de si, configurando-se, teoricamente pensando como uma escrita de si, pois falou (acerca) de si. A necessidade de dizer de si faznos pensar que o outro para quem Santareno escreve, muitas vezes, no blog, não é o outro leitor que pode ler ou não sua escrita. É o próprio Santareno. É o outro ele (ele próprio), o que parece ser ratificado por haver apenas um comentário para a narrativa "Que confusão...", e, mesmo assim, tal comentário não foi comentado ou respondido por Santareno, visto que, ao que tudo indica, ele parece ser o outro de si mesmo. 
Consideramos que há um tom de confissão na escrita da narrativa, especificamente no recorte em questão. Não é uma confissão jurídica de um crime que se cometeu, mas, sim, um encontro com a subjetividade. Segundo Uyeno (2004, p. 4), “constituindo um dos mecanismos que transformam o indivíduo em sujeito, permitindo-lhe uma relação consigo mesmo, a confisssão tem papel central no processo da subjetivação (...)”. No caso da narrativa de Santareno, trata-se de uma confissão que vem em decorrência de uma possível angústia, uma vez que ele, em certo sentido, se sente culpado por não ser tão brasileiro nem mais tão angolano. Portanto, a confissão do imigrante angolano estaria no próprio conflito subjetivo, configurando-se uma confissão de subjetividade, irrompendo traços desta.

Refletindo acerca da imigração na contemporaneidade, vale lembrar do conflito pelo qual o sociólogo Bauman (2005) passou ao ter que decidir entre os hinos da Grã-Bretanha e da Polônia no recebimento do título de doutor honoris causa, na Universidade Charles, de Praga. Isso porque a Grã-Bretanha foi o lugar que escolheu e pelo qual foi escolhido para lecionar, visto que foi proibido de lecionar na Polônia, país onde nasceu, proibição essa decorrente de questões políticas. Tal sociólogo foi contra o sistema unipartidário de seu país de origem e, por isso, foi impedido de ali lecionar, mudando-se para a Inglaterra. Janina, sua esposa, o aconselhou a optar pelo hino da Europa, e, assim, ele o fez, pois “europeu (...) nunca tinha deixado de ser - nascido na Europa, vivendo na Europa, trabalhando na Europa, pensando e sentindo como um europeu" (BAUMAN, 2005, p. 16). No entanto, essa decisão pelo hino europeu foi, segundo esse autor, "includente" e "excludente" ao mesmo tempo, no sentido de unir e anular pontos de referência. Bauman (2005), por ter sido obrigado a se mudar, afirma não haver um lugar em que pudesse se considerar ajustado. Nesse sentido, "em todo e qualquer lugar eu [ele] estava - algumas vezes ligeiramente, outras ostensivamente 'deslocado" (BAUMAN, 2005, p. 18). Essa questão do deslocamento, uma espécie de conflito, abre para pensarmos que a subjetividade não é algo que se escolhe ou controla, mas, sim, algo que é construído ao longo da vida.

\section{Considerações finais}

A subjetividade é construída à medida que o sujeito é subjetivado nas práticas discursivas e se subjetiva por meio do dizer de si e sobre si, dentre outros modos. Ela possui um caráter contraditório, dado o fato de o sujeito advir como resultado de sua sujeição ao universal, mas, ao mesmo tempo, ter a condição de seus efeitos subordinada à singularidade 
de sua existência. Santareno, ao narrar sobre o possível modo como o outro de sua nação o vê, constrói sua subjetividade, a si mesmo, deixando entrever traços que se contradizem: ser isso e/ou ser aquilo? Dito de outra forma, o modo como sua escrita é exercida indicia uma subjetividade que está em suspenso: ser e/ou estar angolano e/ou brasileiro?

Santareno, por meio do funcionamento discursivo dos dêiticos "já", "ainda" e "aqui”" e até da conjunção adversativa "já", deixa perceber uma possível resistência a se deixar "engolir" pelo país de acolhida (Brasil), o que não quer dizer que algo no seu sotaque, na sua maneira de falar, não tenha mudado. Essa mudança é um exemplo do fato de que o sujeito imigrante não mais vai ser o mesmo de quando saiu de sua pátria, entretanto nãø vai ser como aquele da pátria para onde partiu, o que parece fundar (mais) um conflito, uma contradição, na subjetividade.

Diante de uma possível angústia em decorrência do acontecimento da imigração, Santareno parece encontrar uma saída (ou seria uma "cura", ainda que pontual?) para isso ao escrever em blog. É um modo de fazer com que uma possível insatisfação, graças à condição de imigrante, não o imobilize ou o formate. Santareno poderia não ter escrito o que escreveu em blog ou, nem mesmo, ter criado um blog, e ficar se lamentando com o fato da imigração. Contudo, Santareno criou um blog e se propôs a escrever uma narrativa que, pelas próprias características, aponta para uma escrita de si. Isso indicia que a subjetividade do imigrante angolano está sendo vivenciada subjetivamente/singularmente, configurando-se como uma saída subjetiva/singular à formatação/reprodução.

Ao exercer uma escrita de si, Santareno deixa entrever uma resistência a permanecer com sua subjetividade à deriva, embora essa escrita indicie a deriva, o conflito, da subjetividade. De certa forma, é possível compreender que os imigrantes têm o desejo de serem aceito pelo país de acolhida, mas, ao mesmo tempo, resistem a deixar de ser como os conterrâneos do país de origem. No final das contas, pensamos ser possível afirmar que a subjetividade do imigrante parece constituir-se nesse movimento da deriva, como poeticamente sugere Kristeva (1994, p. 16): “ $E u$ faço o que se quer, mas não sou 'eu' - meu ‘eu' está em outro lugar, meu 'eu' não pertence a ninguém, meu 'eu’ não pertence a 'mim'... 'eu' existe?" (grifos da autora). 


\section{Referências}

BAUMAN, Z. Identidade: entrevista a Benedetto Vecchi. Rio de Janeiro: Jorge Zahar Ed., 2005.

CORACINI, M. J. A celebração do outro: arquivo, memória e identidade: línguas (materna e estrangeira), plurilingüismo e tradução. Campinas, SP: Mercado de Letras, 2007.

Os blogs escolares e a escrita de si: entre a redação escolar e os diários virtuais. In: CORACINI, M. J.; UYENO, E. Y.; MASCIA, M. A. A.(orgs.). Da letra ao píxel e do píxel à letra: uma análise discursiva do e sobre o virtual: identidade, leitura e escrita, formação de professores e ensino-aprendizagem de língua. Campinas, SP: Mercado de Letras, 2011.

DEBORD, G. A sociedade do espetáculo. São Paulo: Contraponto, 1997.

FOUCAULT, M. A escrita de si. In: O que é um autor? Lisboa: Passagens, 1992, p. 129160.

A ética do cuidado de si como prática da liberdade. In: . Ética, sexualidade, política. 2. ed. Rio de Janeiro: Forense Universitária, 2006, (Ditos e escritos: V), p. 264-287.

. O sujeito e poder. In: DREYFUS, Hubert; RABINOW, Paul. Michel Foucault, uma trajetória filosófica: para além do estruturalismo e da hermenêutica. Rio de Janeiro: Forense Universitária, 1995.

GUATTARI, F.; ROLNIK, S. Micropolítica. Cartografias do desejo. 6. ed. Petrópolis: Editora Vozes, 2000.

GUIMARÃES, E. A Articulação do texto. Série princípios. 7. ed. São Paulo: Ática, 1999.

ILARI, R. Introdução à semântica: brincando com a gramática. 6. ed. São Paulo: Contexto, 2006.

KRISTEVA, J. Estrangeiros para nós mesmos. Rio de Janeiro: Rocco, 1994.

Profissão Repórter. Programa exibido pela Rede Globo no dia 31 de julho de 2012 com o título "Gringos no Brasil".

REVEL, J. Foucault: conceitos essenciais. São Carlos: Clara Luz, 2005.

SALES, M. Foucault e os modos de subjetivação. In: Anais do XI ANPOF, 2008.

UYENO, E. Y. "Blog": o efeito terapêutico como economia do dispositivo confessional. In: Seminário Internacional Foucault, perspectivas. Clicdata Multimídia Ltda. Florianópolis, SC. 2004.

. Confissões em blogs: a nova prática do sacramento cristão. In: Discutindo literatura, São Paulo, v. 2, p. 36-39, 10 mar. 2005. 
- Hermenêutica de si mesmo: escrita acadêmica, parrehía e subjetividade. In: Linguagem, cognição e afetividade. Taubaté: Cabral Editora, 2006.

- Memória e Diáspora globalizada; a nova cartografia e a identidade múltipla do descendente do imigrante. In: CORACINI, M. J. F. e GHIRALDELO, C. M. (orgs.). Nas Malhas do Discurso: memória, imaginários e subjetividade, formação de professores (línguas materna e estrangeira), leitura e escrita. Pontes Campinas, 2011, p. 193-220.

\section{Blog}

www.angolacontecomigo.blogspot.com.br - Acesso: segundo semestre de 2012.

Artigo recebido em: 28.04.2014

Artigo aprovado em: 26.06.2014 